\title{
The regulation of Enzyme IIA Glc expression controls adenylate cyclase activity in Escherichia coli
}

\author{
Evelyne Krin, Odile Sismeiro, $†$ Antoine Danchin and Philippe N. Bertin $\ddagger$
}

Author for correspondence: Evelyne Krin. Tel: +3301406135 56. Fax: +33014568 8948 . e-mail: ekrin@pasteur.fr

Unité de Génétique des Génomes Bactériens, Institut Pasteur, 28 rue du Docteur Roux, 75724 Paris Cedex 15, France

\begin{abstract}
During the last few years, several genes, such as pap, bgl and flhDC, have been shown to be coregulated by the histone-like nucleoid-structuring (H-NS) protein and the cyclic AMP-catabolite activator protein (CAMP/CAP) complex, suggesting an interaction between both systems in the control of some cellular functions. In this study, the possible effect of H-NS on the CAMP level was investigated. In a CAP-deficient strain, the presence of an hns mutation results in a strong reduction in the amount of CAMP, due to a decrease in adenylate cyclase activity. This is caused by the reduced expression of crr, which encodes the Enzyme IIA Gic of the phosphoenolpyruvate:carbohydrate phosphotransferase system (PTS), from its specific P2 promoter. This leads to a twofold reduction in the global amount of Enzyme IIA Glc, the adenylate cyclase activator, responsible for the decrease in adenylate cyclase activity observed in the hns crp strain.
\end{abstract}

Keywords: catabolite repression, cya, regulatory network

\section{INTRODUCTION}

In enterobacteria, the histone-like nucleoid-structuring (H-NS) protein is one of the most abundant DNAbinding proteins involved in the organization of the bacterial chromosome (Bertin et al., 2001). Numerous phenotypes have been associated with hns mutations, resulting from a modification in the expression of several genes. Most of them are regulated by environmental parameters, such as $\mathrm{pH}$, osmolarity and temperature, or are known to be involved in bacterial virulence (Atlung \& Ingmer, 1997; Laurent-Winter et al., 1997; Hommais et al., 2001).

It has been demonstrated that the H-NS protein interacts with other regulatory systems. For example, the leucineresponsive regulatory protein Lrp regulates the transcription of a number of genes by binding DNA at a specific site located upstream from the transcription start site of the genes (Calvo \& Matthews, 1994). Some

\footnotetext{
† Present address: Genopole, Institut Pasteur, 28 rue du Docteur Roux, 75724 Paris Cedex 15, France.

$\ddagger$ Present address: Laboratory of Microbiology, Radioactive Waste \& Clean-up Division, SCK/CEN, Boeretang 200, 2400 Mol, Belgium.

Abbreviations: CAP, catabolite activator protein; H-NS, histone-like nucleoid-structuring; PTS, phosphoenolpyruvate:carbohydrate phosphotransferase system.
}

of these target genes and the Lrp structural gene itself are regulated by the H-NS protein (Levinthal et al., 1994; Oshima et al., 1995). The H-NS protein also possesses common targets with the cAMP-catabolite activator protein (CAP) complex: nmpC and malT genes (Coll et al., 1994; Johansson et al., 1998) and pap, bgl, mccABCDE and flhDC operons (Forsman et al., 1992; Gonzalez-Pastor et al., 1995; Schnetz \& Wang, 1996; Soutourina et al., 1999). In contrast to its role in the control of $f l h D C$ expression (Bertin et al., 1994; Soutourina et al., 1999), the cAMP-CAP complex acts as an H-NS protein antirepressor in the regulation of pap and bgl operons (Forsman et al., 1992; Schnetz \& Wang, 1996).

The cAMP-CAP complex, which controls the expression of a multitude of genes or operons, has been characterized for its role in catabolite repression. Indeed, high glucose levels reduce Enzyme IIA ${ }^{\text {Glc }}$ phosphorylation, which decreases adenylate cyclase activity and cAMP concentration. This results in a repressed synthesis of the enzymes needed for the catabolism of alternative carbon sources. It is now known that CAP is also involved in the expression of genes needed for adaptation to changes in growth conditions. Moreover, CAP regulates the synthesis of some membrane components, numerous proteins involved in various stresses and some regulator-encoding genes. Finally, it is worth 
mentioning that many CAP-regulated genes are also controlled by other transcription factors (for a review see Busby \& Kolb, 1996).

It has been suggested that the cellular CAP concentration might be somewhat reduced in hns strains (Johansson et al., 1998). As it has been demonstrated that the activity of CAP is mainly modulated by the intracellular level of cAMP (Roy et al., 1983; Kolb et al., 1993), we wanted to know whether the H-NS protein could be involved in the control of the intracellular cyclic AMP (cAMP) concentration. In the present paper, we show that the H-NS protein plays a role in this process by acting on $\mathrm{crr}$ gene expression. The effect on the crr-specific P2 promoter was mainly observable in the absence of CAP and, although the H-NS protein has been considered as a transcriptional repressor, our results constitute a new example of a positive effect of this regulatory protein on bacterial physiology. Moreover, we show for the first time that $\mathrm{crr}$ expression is regulated and that a twofold reduction in the global amount of Enzyme IIA ${ }^{\text {Gle }}$ is sufficient to significantly decrease adenylate cyclase activity and the cAMP level.

\section{METHODS}

Bacterial strains, plasmids and growth conditions. The Escherichia coli $\mathrm{K}-12$ derivative strains and the plasmids used in this work are listed in Table 1. Mutations hns-1001 and hns118 were introduced by P1 transduction as described previously (Bertin et al., 1994). For reasons of incompatibility with the kanamycin resistance marker of the resident plasmid, the $h n s-118$ mutation was used instead of the $h n s-1001$ mutation in $\beta$-galactosidase experiments. All strains were grown at $37^{\circ} \mathrm{C}$ in M63 medium (Miller, 1972), supplemented with glucose $(0.4 \%)$, thiamine $\left(5 \mu \mathrm{g} \mathrm{ml}^{-1}\right)$ and Casamino acids $(0 \cdot 1 \%)$. When required, kanamycin and ampicillin were added at 25 and $100 \mu \mathrm{g} \mathrm{ml}^{-1}$, respectively. Plasmid pDIA3350 was constructed by insertion of the SalI-BamHI fragment of
pDIA3238, corresponding to the full phosphoenolpyruvate:carbohydrate phosphotransferase system (PTS) operon with promoters P0, P1 and P2, into plasmid pDIA3240 (De Reuse et al., 1986). All experiments were performed in accordance with the European regulation requirements concerning the contained use of Genetically Modified Organisms of Group I (agreement no. 2735).

CAMP assay. Total cAMP production was determined by a radioimmunological assay from at least four samples of exponentially growing cells as described by Guidi-Rontani et al. (1981) and Crasnier et al. (1994).

In vitro adenylate cyclase assay. Exponentially growing cell cultures were centrifuged at $9000 \mathrm{~g}$ for $10 \mathrm{~min}$ at $20^{\circ} \mathrm{C}$. The pellet, corresponding to $0.5 \mathrm{~g}$ bacteria, was resuspended in $3 \mathrm{ml} 25 \mathrm{mM}$ Tris $/ \mathrm{HCl}, 10 \mathrm{mM} \mathrm{MgCl}$, pH 8.3, (Tris- $\mathrm{Mg}$ buffer) to obtain a $20 \mathrm{mg} \mathrm{ml}^{-1}$ protein concentration. Bacteria were then broken with the FastPrep System and FastProtein Blue (Bio-101) and centrifuged at $13000 \mathrm{~g}$ at $4{ }^{\circ} \mathrm{C}$. Protein $(0.4-0.8 \mathrm{mg})$ of the bacterial supernatant was added to $1.2 \mathrm{ml}$ of assay mixture (125 mM Tris/ $\mathrm{HCl}, \mathrm{pH} \mathrm{8} 3,50 \mathrm{mM} \mathrm{MgCl}_{2}$, $5 \mathrm{mM}$ dithiothreitol, $5 \mathrm{mM} \mathrm{ATP}$ ) and $4.68 \mathrm{ml}$ Tris-Mg buffer. During incubation at $28^{\circ} \mathrm{C}$, several samples of $1 \mathrm{ml}$ were taken between 0 and $60 \mathrm{~min}$ and heated for $5 \mathrm{~min}$ at $100^{\circ} \mathrm{C}$, according to the method of Joseph et al. (1982). The cAMP synthesized was quantified with the $\operatorname{cAMP}\left[{ }^{125} \mathrm{I}\right]-\mathrm{RIA}$ kit (NEN).

$\boldsymbol{\beta}$-Galactosidase assay. $\beta$-Galactosidase activity was determined by the method of Miller (1992) on exponentially growing cells. The assay was performed on more than three samples from at least two independent cultures.

Determination of the phosphorylation state of Enzyme IIA ${ }^{\mathrm{Glc}}$. The phosphorylation state of Enzyme IIA ${ }^{\text {Glc }}$ was determined with a Western blotting experiment with anti-IIA ${ }^{\mathrm{Glc}}$ antibodies (kindly provided by P. Postma, University of Amsterdam, The Netherlands) on $20 \mu$ protein extracts from strains grown to an $\mathrm{OD}_{600}$ of precisely 0.400 (Takahashi et al., 1998). Immunoblots were scanned with a JX-330 Sharp scanner and quantified using PDI software, PDQuest, based on a SUN computer system.

Table 1. E. coli strains and plasmids used in this study

\begin{tabular}{|c|c|c|}
\hline $\begin{array}{l}\text { Strain or } \\
\text { plasmid }\end{array}$ & Description & Source \\
\hline \multicolumn{3}{|l|}{ Strains } \\
\hline TP2101 & $\mathrm{F}^{-} x y l \Delta l a c X 74 \operatorname{argH} 1$ & Laboratory collection \\
\hline BE1522 & $\mathrm{F}^{-} x y l$ slacX74 argH1 hns-1001:: Tn5seq1 & This study \\
\hline ТР2139 & $\mathrm{F}^{-} x y l \Delta c r p 39 \Delta l a c X 74 \operatorname{argH} 1$ ilvA & Roy et al. (1983) \\
\hline BE1420 & $\mathrm{F}^{-} x y l \Delta c r p 39 \Delta l a c X 74 \operatorname{argH} 1$ ilvA hns-1001::Tn5seq1 & This study \\
\hline BE1421 & $\mathrm{F}^{-}$xyl $\Delta c r p 39 \Delta l a c X 74 \operatorname{argH} 1$ ilvA hns-118:: Tn10 & This study \\
\hline \multicolumn{3}{|l|}{ Plasmids } \\
\hline pDIA1973 & cyaA-lacZ operon fusion & Roy et al. (1988) \\
\hline pDIA3226 & $p t s H-p t s I-l a c Z$ protein fusion & De Reuse \& Danchin (1988) \\
\hline pDIA3238 & $p t s H$-ptsI-crr-lacZ protein fusion & De Reuse \& Danchin (1988) \\
\hline pDIA3247 & ptsH-lacZ protein fusion & De Reuse \& Danchin (1988) \\
\hline pDIA3241 & $p t s H$-lacZ operon fusion & De Reuse \& Danchin (1988) \\
\hline pDIA3242 & $p t s H$-ptsI-lacZ operon fusion & De Reuse \& Danchin (1988) \\
\hline pDIA3350 & $p t s H$-ptsI-crr-lacZ operon fusion & This study \\
\hline pDIA4705 & pBR322 derivative carrying $\mathrm{cr} r$ under anti- $\mathrm{Tc}^{\mathrm{r}}$ promoter & Zeng et al. (1992) \\
\hline
\end{tabular}




\section{RESULTS}

\section{Effect of crp and/or hns mutations on CAMP level}

To determine whether the H-NS protein modulates cAMP synthesis, the total cAMP level was measured in exponentially growing cells of wild-type TP2101 and isogenic strains deficient for the H-NS protein (BE1522), CAP (TP2139) or both regulators (BE1420), by using a radioimmunological method. As expected (Potter et al., 1974; Joseph et al., 1982), the presence of a crp mutation in TP2139 resulted in an important increase in cAMP concentration (more than 300-fold). In contrast, no significant difference was observed in the hns strain BE1522 (Table 2). Moreover, compared to the strain carrying the sole $c r p$ mutation, the presence of both $c r p$ and hns mutations in BE1420 resulted in a more than sixfold reduction in the cAMP concentration (Table 2). This result was confirmed by a cAMP excretion test on MacConkey maltose medium (data not shown). This suggests that the repression by the cAMP-CAP complex seems to be epistatic with regard to the activation by the $\mathrm{H}-\mathrm{NS}$ protein. However, at least in a $\mathrm{crp}$ background, the H-NS protein affects the level of cAMP.

Table 2. cAMP levels in H-NS protein-deficient and/or CAP-deficient strains

Data are the mean values of four samples from two independent cultures that differed by less than $20 \%$.

\begin{tabular}{|lcc|}
\hline Strain & Relevant genotype & $\begin{array}{c}\text { Total cAMP } \\
\left.\text { [pmol (mg protein })^{-1}\right]\end{array}$ \\
\hline TP2101 & Wild-type & 314 \\
BE1522 & hns & 415 \\
TP2139 & crp & 97625 \\
BE1420 & crp hns & 15069 \\
\hline
\end{tabular}

Positive effect of the H-NS protein on the activity and the synthesis of adenylate cyclase in a crp strain

Adenylate cyclase plays a major role in the control of cAMP level in bacterial cells. This enzyme is known to be regulated by CAP at the level of its activity and at the transcriptional level (Aiba, 1985; Inada et al., 1996; Takahashi et al., 1998).

Adenylate cyclase activity was measured with an in vitro assay on exponentially growing cells. A more than 30fold increase in enzyme activity was measured in the crp strain TP2139 [12600 pmol cAMP (mg protein $)^{-1} \mathrm{~min}^{-1}$ ] compared to the wild-type TP2101 [400 pmol cAMP (mg protein $\left.)^{-1} \min ^{-1}\right]$, in accordance with the results of others (Rephaeli \& Saier, 1976; Joseph et al., 1982). In contrast, an eightfold decrease in activity was measured in the crp hns double mutant BE1420 [1600 pmol cAMP (mg protein $\left.)^{-1} \mathrm{~min}^{-1}\right]$ compared to the crp strain. These results are in agreement with the total cAMP level measured in bacterial cultures (Table 2).

To investigate the role of the H-NS protein on the transcription of the adenylate cyclase encoding gene, we measured the activity of a $c y a A-l a c Z$ operon fusion from plasmid pDIA1973 (Roy et al., 1988). Compared to the wild-type TP2101 [6320 Miller units (mg protein) ${ }^{-1}$ ], a moderate increase in $\beta$-galactosidase activity was observed in the crp strain TP2139 (Table 3), in agreement with the data of others (Kawamukai et al., 1985). In contrast, in the crp hns double mutant BE1421 (Table 3), a more than twofold decrease in $\beta$-galactosidase activity was observed compared to that in the crp strain.

\section{Regulation of adenylate cyclase activity by the H-NS protein via the Enzyme IIA ${ }^{\mathrm{Glc}}$ level}

Adenylate cyclase activity is known to be regulated by the PTS via Enzyme IIA ${ }^{\text {Glc }}$ and the cAMP-CAP complex (Levy et al., 1990; Saier et al., 1996; Reddy \& Kamireddi,

Table 3. Effect of the $\mathrm{H}$-NS protein on $\beta$-galactosidase synthesis rate of gene fusions between cyaA, pts $H$, ptsl or crr and lac $Z$

Data are the mean values of more than three samples from at least two independent cultures that differed by less than $10 \%$

\begin{tabular}{|c|c|c|c|}
\hline \multirow[t]{2}{*}{ Plasmid } & \multirow[t]{2}{*}{ lac $Z$ fusion } & \multicolumn{2}{|c|}{$\begin{array}{c}\beta \text {-Galactosidase activity } \\
{\left[\text { Miller units }(\mathrm{mg} \text { protein })^{-1}\right] \text { in: }}\end{array}$} \\
\hline & & $\mathrm{TP} 2139(\mathrm{crp})$ & BE1421 (crp hns) \\
\hline pDIA1973 & cyaA operon & 8950 & 3470 \\
\hline pDIA3241 & ptsH operon & 2730 & 2000 \\
\hline pDIA3247 & ptsH protein & 5370 & 3870 \\
\hline pDIA3242 & $p t s H$-ptsI operon & 2190 & 2150 \\
\hline pDIA3226 & $p t s H$-ptsI protein & 1420 & 1910 \\
\hline pDIA3350 & $p t s H$-ptsI-crr operon & 10690 & 2870 \\
\hline pDIA3238 & $p t s H$-ptsI-crr protein & 6210 & 3150 \\
\hline
\end{tabular}




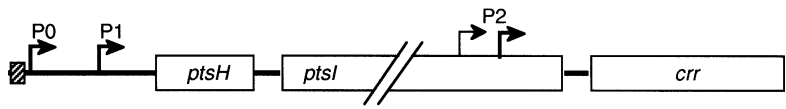

$100 \mathrm{bp}$

Fig. 1. Organization of the pts operon (De Reuse \& Danchin 1988; De Reuse et al., 1992). Open boxes represent the $p t s H_{\text {, }}$ ptsl and crr coding regions. The transcriptional start sites from P0, P1 and P2 promoters are indicated by arrows. The major transcriptional start sites are indicated by bold arrows and the binding site for the CAP-cAMP complex is shown by a hatched box.

1998). The HPr protein could also be involved in this process (Peterkofsky et al., 1995). Although the three PTS genes $p t s H$, $p t s I$ and $c r r$, which encode the proteins HPr, Enzyme I and Enzyme IIA ${ }^{\text {Gle }}$, respectively, are considered to be part of a single operon, transcription is known to be initiated from three distinct promoters, P0, P1 and P2 (Fig. 1) (De Reuse \& Danchin, 1988; De Reuse et al., 1992). As the decrease in cyaA-lacZ activity does not seem to be sufficient to explain the strong decrease in adenylate cyclase activity measured in the crp hns double mutant BE1421 (see above), the expression level of $p t s H$, $p t s I$ and $c r r$ was analysed using protein and operon fusions (De Reuse \& Danchin, 1988). In the crp strain, the lack of H-NS protein had only a minor effect on the expression of both ptsH-lacZ and ptsI-lacZ fusions, which are exclusively under the control of promoters $P 0$ and P1, i.e. a 1.3-fold decrease and 1·3-fold increase, respectively (Table 3 ). In contrast, $c r r$ expression, which is under the control of the three promoters, showed a 3.7 -fold and twofold decrease in the $\beta$-galactosidase activity of the crr-lacZ transcriptional and protein fusion, respectively, in the crp hns double mutant BE1421 compared to the crp strain (Table 3). This suggests that the H-NS protein exerts a positive and specific effect on $\mathrm{cr}$ transcription from the $\mathrm{P} 2$ promoter.

The Enzyme IIA ${ }^{\text {Glc }}$ is known to be phosphorylated by the phosphorylated HPr protein (HPr-P), which is itself phosphorylated by Enzyme I-P (Postma \& Lengeler, 1985). Phosphorylated Enzyme IIA ${ }^{\text {Gle }}$ is known to activate adenylate cyclase while the unphosphorylated form has no effect on enzyme activity (Den Blaauwen \& Postma, 1985; Crasnier \& Danchin, 1990; Reddy \& Kamireddi, 1998; Takahashi et al., 1998). Moreover, it has been supposed that the global regulation of adenylate cyclase activity depends on the sole phosphorylation state of Enzyme IIA ${ }^{\text {Glc }}$. Indeed, the major effect of the cAMP-CAP complex on adenylate cyclase activity results from the decrease in Enzyme IIA ${ }^{\text {Gle }}$ phosphorylation (Saier et al., 1996; Crasnier-Mednansky et al., 1997; Reddy \& Kamireddi, 1998; Takahashi et al., 1998). To determine the phosphorylated state of Enzyme IIA $^{\text {Gle }}$ in the different strains, a Western blotting experiment was performed with anti-IIA ${ }^{\mathrm{Gle}}$ antibodies on protein extracts from strains grown to an $\mathrm{OD}_{600}$ of 0.400 (Takahashi et al., 1998). After quantification, only $14 \%$ of Enzyme IIA ${ }^{\mathrm{Gle}}$ was phosphorylated in wild-type

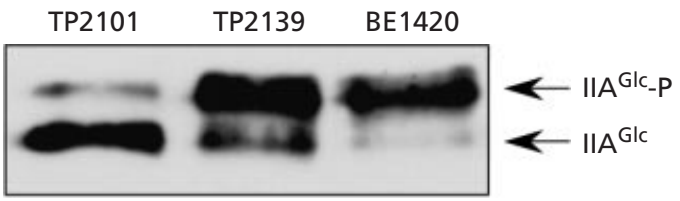

Fig. 2. Phosphorylation state and amount of Enzyme $\| A^{G l c}$ in wild-type (TP2101), crp (TP2139) and crp hns (BE1420) strains. The two forms of the enzyme were visualized on a Western blot using anti-Enzyme IIA ${ }^{\mathrm{Gl}}$ antibodies and quantified using PDI software, PDQuest. The result is representative of two experiments performed with $20 \mu \mathrm{l}$ protein extract from two independent cultures at an $O D_{600}$ of precisely 0.400 .

strain TP2101, while 82 and $93 \%$ was phosphorylated in the crp (TP2139) and crp hns (BE1420) strains, respectively (Fig. 2). The proportion of the two forms of Enzyme IIA ${ }^{\text {Glc }}$ was similar in both crp and crp hns mutant strains. This suggests that the small variation observed on $p t s H$ and $p t s I$ expression has no effect on the phosphorylation state of Enzyme IIA ${ }^{\text {Gle }}$. No significant difference in the amount of Enzyme IIA ${ }^{\text {Glc }}$ was observed between wild-type and crp strains (Fig. 2). In contrast, a twofold decrease in the amount of Enzyme IIA $^{\text {Gle }}$ was measured in the crp hns double mutant compared to the crp strain (Fig. 2). This result is in agreement with the reduced expression of the crr-lacZ fusions observed in such a strain (Table 3). Similarly, a $51 \%$ reduction in the amount of Enzyme IIA ${ }^{\text {Glc }}$ was measured in the hns strains compared to that in the wildtype.

To discover whether the reduced amount of Enzyme IIA $^{\text {Gle }}$ measured in the crp hns strain (Fig. 2) was sufficient to explain the decrease in adenylate cyclase activity, we determined this activity in the double mutant BE1420 containing plasmid pDIA4705 carrying the $c r r$ gene. The presence of this plasmid in a $\Delta c r r$ strain has been shown to restore the wild-type cAMP level and glucose transport (Zeng et al., 1992). The activity measured in the crp bns mutant containing plasmid pDIA4705, 11400 pmol cAMP (mg protein) ${ }^{-1} \min ^{-1}$, was similar to that obtained in the TP2139 crp strain [12600 pmol cAMP (mg protein) $\left.{ }^{-1} \mathrm{~min}^{-1}\right]$. This is consistent with the Western blotting experiment which showed that a similar amount of Enzyme IIA ${ }^{\text {Glc }}$ was present in both TP2139 and BE1420(pDIA4705) (data not shown). This demonstrated that the variation in adenylate cyclase activity resulting from an $h n s$ mutation depends on the reduced amount of Enzyme IIA ${ }^{\text {Gle }}$ present in the cells rather than the effect the H-NS protein on cyaA gene expression (Table 2).

\section{DISCUSSION}

In E. coli, adenylate cyclase activity is known to be very low in a wild-type genetic context. Indeed, Enzyme IIA $^{\text {Gle }}$, which is the major activator of this activity, is mainly in an unphosphorylated form due to the presence 
of a high concentration of cAMP-CAP complex (Saier et al., 1996; Crasnier-Mednansky et al., 1997; Reddy \& Kamireddi, 1998; Takahashi et al., 1998). Only the phosphorylated form of the enzyme plays a role as activator. This phosphorylation results from a transfer of the phosphoryl group from phosphoenolpyruvate to Enzyme IIA Gle via Enzyme I and $\mathrm{HPr}$ (Postma \& Lengeler, 1985). The three PTS genes ptsH, ptsI and crr, which encode the proteins HPr, Enzyme I and Enzyme IIA $^{\text {Gle }}$, respectively, belong to a single operon. However, transcription is initiated from three distinct promoters (Fig. 1). Both ptsH and ptsI depend on P0 and P1 promoters, while $\mathrm{crr}$ is controlled by the three promoters, P2 being responsible for $80 \%$ of total $\mathrm{crr}$ mRNA synthesis (De Reuse \& Danchin, 1988; De Reuse et al., 1992). Transcriptional regulation by glucose, the cAMPCAP complex and the global repressor Mlc has been observed on promoter P0 (De Reuse et al., 1992; Ryu \& Garges, 1994; Tanaka et al., 1999), while promoter P1 is known to be regulated by the fructose repressor FruR (Ryu et al., 1995). However, no regulatory mechanism has been shown to affect promoter P2.

Our results demonstrate, for the first time, that $\mathrm{crr}$ is regulated at the transcriptional level. This regulation only affects the P2-specific promoter and has almost no effect on the two other promoters of the PTS operon. The H-NS protein controls the expression of numerous genes involved in bacterial adaptation to environmental changes (Hommais et al., 2001) and it is generally considered as a transcriptional repressor. Although the mechanism, which could be indirect, remains to be determined, our results constitute a new example of the positive effect of this regulatory protein on bacterial physiology. Recently, the existence of a complex between HhA and the H-NS protein has been shown to be involved in the regulation of the haemolysin operon in $E$. coli (Nieto et al., 2000). Moreover, an hha mutation results in a fivefold decrease in Enzyme IIA ${ }^{\text {Gle }}$ in rich medium under high osmolarity conditions (Balsalobre et al., 1999). Taken together, these obervations may suggest an interaction of both proteins in the regulation of $\mathrm{crr}$ expression. However, in contrast to the H-NS protein (Table 3 and Fig. 2), the effect of HhA on Enzyme IIA ${ }^{\text {Glc }}$ was only observed in conditions of high osmolarity, suggesting that the two regulatory proteins affect $\mathrm{cr}$ expression by a different mechanism. Finally, the repression by the cAMP-CAP complex is predominant with regard to the activation by the H-NS protein. Indeed, in the presence of the cAMP-CAP complex, only a small fraction of Enzyme IIA ${ }^{\text {Glc }}$ was phosphorylated (Fig. 2). This suggests that adenylate cyclase has its lowest activity in the wild-type strain, which could explain that a twofold alteration in the amount of Enzyme IIA ${ }^{\text {Gle }}$ in hns strains has no major effect on adenylate cyclase activation.

We also showed that, despite a large excess of Enzyme IIA $^{\text {Glc }}$ in the cell [about 15000 Enzyme IIA ${ }^{\text {Gle }}$ phosphorylated molecules in comparison with 15-50 adenylate cyclase molecules (Yang \& Epstein, 1983; Mitchell et al., 1987)], a twofold variation in its accumulation level resulted in an eightfold decrease in adenylate cyclase activity. In a glucose-rich medium, the phosphorylated form of Enzyme IIA ${ }^{\text {Glc }}$ interacts preferentially with the glucose permease (Enzyme IIBC $^{\text {Glc }}$ ) to allow the entry of glucose into the cell. This suggests that the affinity of phosphorylated Enzyme IIA Glc is much lower for adenylate cyclase, or for the putative intermediary that could activate it (Saier et al., 1996), than for glucose permease. Depending on environmental conditions, adenylate cyclase may be regulated either by the amount or by the phosphorylation of Enzyme IIA ${ }^{\text {Gle }}$.

\section{ACKNOWLEDGEMENTS}

We are grateful to I. Martin-Verstraete for critical reading of the manuscript, H. De Reuse for helpful advice and to C. Laurent-Winter for technical assistance. We thank N. Guiso for providing us with an in vitro adenylate cyclase assay protocol and to P. Postma for the gift of anti-IIA ${ }^{\mathrm{Glc}}$ antibodies. Financial support came from the Institut Pasteur and the Centre National de la Recherche Scientifique (URA 1129).

\section{REFERENCES}

Aiba, H. (1985). Transcription of the Escherichia coli adenylate cyclase gene is negatively regulated by cAMP-cAMP receptor protein. J Biol Chem 260, 3063-3070.

Atlung, T. \& Ingmer, H. (1997). H-NS: a modulator of environmentally regulated gene expression. Mol Microbiol 24, 7-17.

Balsalobre, C., Johansson, J., Uhlin, B. E., Juarez, A. \& Munoa, F. J. (1999). Alterations in protein expression caused by the $h b a$ mutation in Escherichia coli: influence of growth medium osmolarity. J Bacteriol 181, 3018-3024.

Bertin, P., Terao, E., Lee, E. H., Lejeune, P., Colson, C., Danchin, A. \& Collatz, E. (1994). The H-NS protein is involved in the biogenesis of flagella in Escherichia coli. J Bacteriol 176, 5537-5540.

Bertin, P., Hommais, F., Krin, E., Soutourina, O., Tendeng, C., Derzelle, S. \& Danchin, A. (2001). H-NS and H-NS-like proteins in Gram-negative bacteria and their multiple role in the regulation of bacterial metabolism. Biochimie 83, 235-241.

Busby, S. \& Kolb, A. (1996). The CAP modulon. In Regulation of Gene Expression in Escherichia coli, pp. 255-279. Edited by E. C. C. Lin \& A. S. Lynch. Austin, TX: R. G. Landes.

Calvo, J. M. \& Matthews, R. (1994). The leucine-responsive regulatory protein, a global regulator of metabolism in Escherichia coli. Microbiol Rev 58, 466-490.

Coll, J. L., Heyde, M. \& Portalier, R. (1994). Expression of the $n m p C$ gene of Escherichia coli $\mathrm{K}-12$ is modulated by external $\mathrm{pH}$. Identification of $c i s$-acting regulatory sequences involved in this regulation. Mol Microbiol 12, 83-93.

Crasnier, M. \& Danchin, A. (1990). Characterization of Escherichia coli adenylate cyclase mutants with modified regulation. J Gen Microbiol 136, 1825-1831.

Crasnier, M., Dumay, V. \& Danchin, A. (1994). The catalytic domain of Escherichia coli K-12 adenylate cyclase as revealed by deletion analysis of the cya gene. Mol Gen Genet 243, 409-416.

Crasnier-Mednansky, M., Park, M. C., Studley, W. K. \& Saier, M. H., Jr (1997). Cra-mediated regulation of Escherichia coli adenylate cyclase. Microbiology 143, 785-792.

Den Blaauwen, J. L. \& Postma, P. W. (1985). Regulation of cyclic AMP synthesis by enzyme III ${ }^{\text {Gle }}$ of the phosphoenolpyru- 
vate: sugar phosphotransferase system in crp strains of Salmonella typhimurium. J Bacteriol 164, 477-478.

De Reuse, H. \& Danchin, A. (1988). The $p t s H$, ptsI, and $c r r$ genes of the Escherichia coli phosphoenolpyruvate-dependent phosphotransferase system: a complex operon with several modes of transcription. J Bacteriol 170, 3827-3837.

De Reuse, H., Touati, E., Glaser, P. \& Danchin, A. (1986). Low copy number plasmid vectors for gene cloning and for monitoring gene expression. FEMS Microbiol Lett 37, 193-197.

De Reuse, H., Kolb, A. \& Danchin, A. (1992). Positive regulation of the expression of the Escherichia coli pts operon. Identification of the regulatory regions. J Mol Biol 226, 623-635.

Forsman, K., Sondén, B., Göransson, M. \& Uhlin, B. E. (1992). Antirepression function in Escherichia coli for the cAMP-cAMP receptor protein transcriptional activator. Proc Natl Acad Sci US A 89, 9880-9884.

Gonzalez-Pastor, J. E., San Millan, J. L., Castilla, M. A. \& Moreno, F. (1995). Structure and organization of plasmid genes required to produce the translation inhibitor microcin C7. J Bacteriol 177, $7131-7140$.

Guidi-Rontani, C., Danchin, A. \& Ullmann, A. (1981). Isolation and characterization of an Escherichia coli mutant affected in the regulation of adenylate cyclase. J Bacteriol 148, 753-761.

Hommais, F., Krin, E., Laurent-Winter, C., Soutourina, O., Malpertuy, A., Le Caer, J. P., Danchin, A. \& Bertin, P. (2001). Large-scale monitoring of pleiotropic regulation of gene expression by the prokaryotic nucleoid-associated protein, H-NS. Mol Microbiol 40, 20-36.

Inada, T., Takahashi, H., Mizuno, T. \& Aiba, H. (1996). Down regulation of cAMP production by cAMP receptor protein in Escherichia coli: an assessment of the contributions of transcriptional and posttranscriptional control of adenylate cyclase. Mol Gen Genet 253, 198-204.

Johansson, J., Dagberg, B., Richet, E. \& Uhlin, B. E. (1998). H-NS and StpA proteins stimulate expression of the maltose regulon in Escherichia coli. J Bacteriol 180, 6117-6125.

Joseph, E., Bernsley, C., Guiso, N. \& Ullmann, A. (1982). Multiple regulation of the activity of adenylate cyclase in Escherichia coli. Mol Gen Genet 185, 262-268.

Kawamukai, M., Kishimoto, J., Utsumi, R., Himeno, M., Komano, T. \& Aiba, H. (1985). Negative regulation of adenylate cyclase gene (cya) expression by cyclic AMP-cyclic AMP receptor protein in Escherichia coli: studies with cya-lac protein and operon fusion plasmids. J Bacteriol 164, 872-877.

Kolb, A., Busby, S., Buc, H., Garges, S. \& Adhya, S. (1993). Transcriptional regulation by cAMP and its receptor protein. Annu Rev Biochem 62, 749-795.

Laurent-Winter, C., Ngo, S., Danchin, A. \& Bertin, P. (1997). Role of Escherichia coli histone-like nucleoid structuring protein in bacterial metabolism and stress response: identification of targets by two-dimensional electrophoresis. Eur J Biochem 244, 767-773.

Levinthal, M., Lejeune, P. \& Danchin, A. (1994). The H-NS protein modulates the activation of the ilvIH operon of Escherichia coli K12 by Lrp, the leucine regulatory protein. Mol Gen Genet 242, 736-743.

Levy, S., Zeng, G.-Q. \& Danchin, A. (1990). Cyclic AMP synthesis in Escherichia coli strains bearing known deletions in the pts phosphotransferase operon. Gene 86, 27-33.

Miller, J. H. (1972). Experiments in Molecular Genetics. Cold Spring Harbor, NY: Cold Spring Harbor Laboratory.

Miller, J. H. (1992). A Short Course in Bacterial Genetics: a Laboratory Manual and Handbook for Escherichia coli and
Related Bacteria. Cold Spring Harbor, NY: Cold Spring Harbor Laboratory.

Mitchell, W. J., Saffen, D. W. \& Roseman, S. (1987). Sugar transport by the bacterial phosphotransferase system: in vivo regulation of lactose transport in Escherichia coli by III $^{\mathrm{Glc}}$, a protein of the phosphoenolpyruvate:glucose phosphotransferase system. J Biol Chem 262, 16254-16260.

Nieto, J. M., Madrid, C., Prenafeta, A., Miquelay, E., Balsalobre, C., Carrascal, M. \& Juarez, A. (2000). Expression of the hemolysin operon in Escherichia coli is modulated by a nucleoid-protein complex that includes the proteins Hha and H-NS. Mol Gen Genet 263, 349-358.

Oshima, T., Ito, K., Kabayama, H. \& Nakamura, Y. (1995). Regulation of $\operatorname{lr} p$ gene expression by H-NS and Lrp proteins in Escherichia coli: dominant negative mutations in lrp. Mol Gen Genet 247, 521-528.

Peterkofsky, A., Seok, Y.-J., Amin, N. \& 8 other authors (1995). The Escherichia coli adenylyl cyclase complex: requirement of PTS proteins for stimulation by nucleotides. Biochem 34, 89508959.

Postma, P. W. \& Lengeler, J. W. (1985). Phosphoenolpyruvate: carbohydrate phosphotransferase system of bacteria. Microbiol Rev 49, 232-269.

Potter, K., Chaloner-Larsson, G. \& Yamazaki, H. (1974). Abnormally high rate of cyclic AMP excretion from an Escherichia coli mutant deficient in cyclic AMP receptor protein. Biochem Biophys Res Commun 57, 379-385.

Reddy, P. \& Kamireddi, M. (1998). Modulation of Escherichia coli adenylyl cyclase activity by catalytic-site mutants of protein IIA ${ }^{\text {Glc }}$ of the phosphoenolpyruvate: sugar phosphotransferase system. $J$ Bacteriol 180, 732-736.

Rephaeli, A. W. \& Saier, M. H., Jr (1976). Effects of crp mutations on adenosine $3^{\prime}, 5^{\prime}$-monophosphate metabolism in Salmonella typhimurium. J Bacteriol 127, 120-127.

Roy, A., Haziza, C. \& Danchin, A. (1983). Regulation of adenylate cyclase synthesis in Escherichia coli: nucleotide sequence of the control region. EMBO J 2, 791-797.

Roy, A., Glaser, P. \& Danchin, A. (1988). Aspects of the regulation of adenylate cyclase synthesis in Escherichia coli K12. J Gen Microbiol 134, 359-367.

Ryu, S. \& Garges, S. (1994). Promoter switch in the Escherichia coli pts operon. J Biol Chem 269, 4767-4772.

Ryu, S., Ramseier, T. M., Michotey, V., Saier, M. H., Jr \& Garges, S. (1995). Effect of the FruR regulator on transcription of the $p t s$ operon in Escherichia coli. J Biol Chem 270, 2489-2496.

Saier, M. H., Jr, Ramseier, T. M. \& Reizer, J. (1996). Regulation of carbon utilization. In Escherichia coli and Salmonella: Cellular and Molecular Biology, pp. 1325-1343. Edited by F. C. Neidhardt \& others. Washington, DC: American Society for Microbiology.

Schnetz, K. \& Wang, J. C. (1996). Silencing of the Escherichia coli bgl promoter: effects of template supercoiling and cell extracts on promoter activity in vitro. Nucleic Acids Res 24, 2422-2428.

Soutourina, O., Kolb, A., Krin, E., Laurent-Winter, C., Rimsky, S., Danchin, A. \& Bertin, P. (1999). Multiple control of flagellum biosynthesis in Escherichia coli: role of H-NS protein and the cyclic AMP-catabolite activator protein complex in transcription of the flhDC master operon. J Bacteriol 181, 7500-7508.

Takahashi, H., Inada, T., Postma, P. \& Aiba, H. (1998). CRP downregulates adenylate cyclase activity by reducing the level of phosphorylated IIA ${ }^{\mathrm{Gle}}$, the glucose-specific phosphotransferase protein, in Escherichia coli. Mol Gen Genet 259, 317-326.

Tanaka, Y., Kimata, K., Inada, T., Tagami, H. \& Aiba, H. (1999). 
Negative regulation of the pts operon by Mlc: mechanism underlying glucose induction in Escherichia coli. Genes Cells 4, 391-399.

Yang, J. K. \& Epstein, W. (1983). Purification and characterization of adenylate cyclase from Escherichia coli K12. J Biol Chem 258, 3750-3758.

Zeng, G. Q., De Reuse, H. \& Danchin, A. (1992). Mutational analysis of the enzyme III ${ }^{\text {Gle }}$ of the phosphoenolpyruvate phosphotransferase system in Escherichia coli. Res Microbiol 143, 251-261.

Received 27 November 2001; revised 21 January 2002; accepted 23 January 2002. 